\title{
LA DIMENSIÓN TEATRAL EN GILLES DELEUZE
}

\author{
The theatrical dimension in Gilles Deleuze \\ Fabián Videla Zavala \\ Universidad de Valparaíso, Valparaíso, Chile \\ fabianvidela.z@gmail.com
}

\section{Resumen}

Se propone desarrollar el vínculo entre el teatro y el pensamiento de Gilles Deleuze, al interior del programa metafísico presente en Diferencia y repetición. Para ello, primero, se esbozará el vínculo entre la inversión del platonismo y la potencia del simulacro teatral en el pensamiento deleuziano. Segundo, se demostrará que éste último se enuncia desde una ruptura con aquella tradición filosófica marcada por una primera lectura representacional del teatro. Finalmente, dicha ruptura se inscribirá en el interés de Deleuze por una comprensión inventiva de las formas de expresión filosóficas, destinada a reformular los límites y tentativas del pensar.

Palabras clave: teatro, Gilles Deleuze, simulacro, representación, diferencia.

\begin{abstract}
It is proposed to develop the bond between theater and Gilles Deleuze's thought to the inside of the metaphisical program present in Difference and repetition. For this, first, there will be outlined the bond between the inversion of platonism and the power of theater simulation in Deleuze's thought. Secondly, there will be proved that Deleuze's thought is oultined from a rupture with that philosophical tradition marked by a first representational reading of theater. Finally, that rupture will be inscribed in Deleuze's interest for an inventive comprehension of the philosophical expression forms, destined to reformulate boundaries and thinking attempts.
\end{abstract}

Keywords: theater, Gilles Deleuze, simulation, representation, difference.

Fecha de Recepción: 02/05/2019 - Fecha de Aceptación: 28/07/2019 


\section{Deleuze y el problema teatral}

Existe en lo profundo del pensamiento de Gilles Deleuze una inquietud teatral disipada en su programa metafísico. Se tratará de una tradición que pasa por Nietzsche (2015) y Artaud (2014) y reclama acabar con el concepto imitativo del arte: la estética aristotélica en la que se reconoce la metafísica occidental del arte. En efecto, tal como señaló tempranamente Nietzsche, el teatro perfectamente significante, heredero de Aristóteles, ha descuidado el trabajo de fuerzas y potencias afectivas del acontecimiento teatral ( $c f .2015$ 49). En él la representación consiste en una dependencia de lo visible con respecto a la designación de la palabra. La enigmática escena teológica que determina el acontecimiento teatral, también descrita por Artaud, que suprime el cuerpo y lo gobierna a distancia (cf. Derrida 1989 312). Pues, en la jerarquía aristotélica de los diversos órdenes del fenómeno teatral, la palabra, a saber, el entramado de argumentos al interior del texto dramático sobresale por sobre su eventual puesta en escena (Poet. 1450a). Será en este oscilar entre teatro y filosofía que Deleuze inquiere un firme desprendimiento de los elementos de poder del teatro que aseguraban su coherencia temática en su representación sobre la escena, su privilegio de la presencia y la visibilidad ( $c f$. Chevallier 2015 16). Dicho de otro modo, Deleuze insistirá en la búsqueda de una matriz teatral amputada de sus formas de poder gravitantes, que daban consistencia y sosiego a su entramado sensible, a favor de un estado de constante variación y flujo de sus elementos (cf. Deleuze 2003 81).

El lector deleuziano puede advertir el hecho de que Deleuze no fue un hombre de teatro, más bien el grosor de su preocupación estética se inclinó por otras formas de expresión artísticas (la pintura, el cine y la literatura); sin embargo, asumiendo el peso de esta observación, ya señalada por Alain Badiou ( $c f .2005$ 116), el teatro juega un rol fundamental en su pensamiento pese a ser abordado con precisión sólo en tres ocasiones ${ }^{1}$. Considerando esta advertencia preliminar, las principales inquietudes que nos propondremos abordar en la presente investigación apuntan a precisar la naturaleza de este problema en cuestión. En ese sentido, se propone identificar su importancia al interior del pensamiento deleuziano, trazando el recorrido conceptual que nos permita comprender los alcances de aquella enigmática teatralización de la filosofía insinuada por Deleuze en la parte introductoria de Diferencia y repetición: "La búsqueda de nuevos medios de expresión filosófica fue inaugurada por Nietzsche, y debe ser proseguida hoy relacionándola con la renovación de algunas otras artes, como el teatro o el cine"

1 Según el año original de publicación: 1) Diferencia y repetición (1968); 2) Un manifiesto menos (1979);

2) El agotado (1992). 
(2012 18). Tal como veremos, en Deleuze se hace patente la preocupación por imbricar, de manera sutil, el teatro y la filosofía:

En este sentido hay algo completamente nuevo que comienza con Kierkegaard y Nietzsche. Ya no reflexionan sobre el teatro a la manera hegeliana. Tampoco hacen un teatro filosófico. Inventan, en la filosofía, un equivalente increíble del teatro, y con ello, fundan ese teatro del porvenir, al mismo tiempo que una filosofía nueva (Id. 34)

En conformidad a esto, la estrategia de esta investigación consiste en contextualizar una articulación del pensamiento de Deleuze en torno a la cuestión teatral en tanto que esta última deviene problema filosófico. Se tratará de un tópico recurrente para el pensamiento francés contemporáneo, por ejemplo, Philippe Lacoue-Labarthe (2010) sostiene una indagación sobre el vínculo entre problema de la mímesis teatral y el pensamiento especulativo y ontológico. Alain Badiou en Rapsodia para el teatro elabora una defensa sistemática del arte teatral.

\section{La inversión del platonismo a través de la dimensión teatral}

A medida que transcurre El Sofista, nos comenta Deleuze en Lógica del sentido, más dificultoso se hace el diferenciar al interior del diálogo entre la figura de Sócrates y aquel elemento desde el cual tan acérrimamente, Platón, pretendía imperiosamente desmarcarse: el sofista. El entrampamiento platónico se direccionará en acorralar al sofista a partir de conceptos aporéticos revestidos de un carácter indudablemente falso que nos trasladan a pensar la difusa posibilidad de que "lo que no es" (tò mê òn), "sea" (tò ón). Siguiendo a Deleuze el platonismo en tanto que doctrina del juicio introduce la trascendencia en el seno de lo inmanente, instaurando un fundamento capaz de juzgar las diversas pretensiones de los participantes en torno a la unidad de la Idea. Para explicar esto, nos afrontaremos minuciosamente a aquel nunca ingenuo gesto inaugural de la metafísica platónica sostenida como proceso de selección moral, en la búsqueda de aquel punto relevante que amenaza con franquear en lo más profundo de la filosofía platónica y el dominio soberano de la filosofía representacional ${ }^{2}$. El problema, entonces, será percibido en el desvelamiento

\footnotetext{
${ }^{2}$ Para Deleuze en Lógica del sentido y, posteriormente también en Diferencia y repetición, con Platón se marca el hito inaugural de la filosofía representacional: “El platonismo funda así todo el ámbito que la filosofía reconocerá como suyo: el ámbito de la representación lleno de copias-iconos, y definido no en relación extrínseca a un objeto sino en relación intrínseca al modelo o fundamento" (1989 260). Porque el platonismo es una operación triple que instaura el dominio de la representación en el pensamiento: 1) el establecimiento de un modelo (lo mismo); 2) selección de la semejanza (la copia); 3) borradura y expulsión de la diferencia (lo otro). La expulsión de la diferencia al interior de la triple operación platónica resulta necesaria para dar a la trascendencia un sentido filosófico plausible, en efecto, siguiendo el temprano estudio de la escena de la filosofía francesa Lo mismo y lo
} 
de la teoría de la Ideas como doctrina selectiva del juicio, que oscila, legítimamente, en la expulsión de la diferencia. Es decir, su desnaturalización mediante su captura representacional:

El Sofista contiene la aventura más extraordinaria del platonismo: a fuerza de buscar por el lado del simulacro y de asomarse hacia su abismo, Platón, en el fulgor repentino de un instante, descubre que éste no es simplemente una copia falsa, sino que pone en cuestión las nociones mismas de copia... y de modelo. La definición final del sofista nos lleva a un punto en donde ya no podemos distinguirlo del propio Sócrates: el ironista que opera en privado con argumentos breves. ¿No era preciso llevar la ironía hasta ahí? ¿No era necesario que Platón fuese el primero que indicara esta dirección de la inversión del platonismo? (Deleuze 1989 257).

En este marco, la contrariedad de la filosofía platónica es delimitada por Deleuze en torno a una incisiva interrogante: ¿acaso aquel elemento desestabilizador para la filosofía platónica se encuentra en el seno del propio platonismo? Platón fue el primero en señalar la dirección de la inversión del platonismo, en el impase de una dualidad más profunda y socavada que las escisiones: inteligible-sensible, ideamateria, idea-cuerpos, modelo-copia. Se trataría más bien de una dualidad que guardaría relación con los cuerpos sensibles y la materia misma, la división platónica entre la copia y el simulacro:

Partíamos de una primera determinación del motivo platónico: distinguir la esencia y la apariencia, lo inteligible y lo sensible, la Idea y la imagen, el original y la copia, el modelo y el simulacro. Pero ya veremos que estas expresiones no son válidas. La distinción se desplaza entre dos tipos de imágenes. Las copias son poseedoras de segunda, pretendientes bien fundados, garantizados por la semejanza; los simulacros están, como los falsos pretendientes, construidos sobre una disimilitud, y poseen una perversión y una desviación esenciales. Es en este sentido que Platón divide en dos el dominio de las imágenes-ídolos: por una parte las copias-iconos, por otra los simulacros-fantasmas (Deleuze 1989 258).

Aquello parece percibirse -nos comenta Deleuze- en la oquedad de las divisiones platónicas, el simulacro vendría a esquivar la acción estabilizadora de la Idea impugnando tanto el modelo como la copia. Atendiendo a dicho riesgo Platón pretende asegurar el triunfo de las copias por sobre los simulacros -aquí, resuena

otro de Vicent Descombes: “Deleuze llama a este pensamiento 'filosofía de la representación'. Está sometida a la autoridad del principio de identidad, cuyo sello encontramos en el prefijo reiterativo RE- de la palabra "representación": todo debe ser re-presentado, a fin de ser re-encontrado como lo mismo; de esta filosofía se desprende que lo desconocido sólo es un conocido aún no reconocido, que aprender es acordarse, encontrar es volver a encontrar, salir es volver, etc. Por ello lo que escapa a este racionalismo es la diferencia como tal. La diferencia entre encontrar y reencontrar es la distancia que separa a una experiencia de su reiteración" (1988 201). Es decir, será aquel álgido momento extremo de la representación, que en su transparencia develada, poseerá la facultad de nombrar todas las diferencias. 
la severidad del gesto de la expulsión de las artes del Estado platónico-, prohibir que los simulacros afloren en la superficie poblando al mundo de representaciones. Por lo que, sospechosamente, la motivación de la selección platónica responderá a criterios morales y no selectivos (cf. Deleuze 2012 393).

Podemos conjeturar entonces que este arraigo del platonismo se perfila en un dar cuenta cuál es el pretendiente más correcto para representar a la Idea, manejando el descontrol propio del simulacro en relación con su fundamento correspondiente:

El simulacro se construye sobre una disparidad, sobre una diferencia; interioriza una disimilitud. Es por lo que, incluso, no podemos definirlo en relación con el modelo que se impone a las copias, modelo de lo Mismo del que deriva la semejanza de las copias. Si el simulacro tiene aún un modelo, es un modelo diferente, un modelo de lo Otro, del que deriva una desemejanza interiorizada (Deleuze 1989 259).

Para poder entender esto indagaremos en el rol del simulacro dentro del platonismo, en tanto que confiere la pérdida de la univocidad del sentido en la asignación y distribución de identidades fijas: "Si decimos del simulacro que es una copia de copia, icono infinitamente degradado, una semejanza infinitamente disminuida, dejamos de lado lo esencial [...] La copia es una imagen dotada de semejanza, el simulacro una imagen sin semejanza" (Deleuze 1989 259). Entre la necesidad y lo universal, la Idea es dispuesta por Platón como aquello que posee la cualidad primera, debiendo permitir según la naturaleza de la participación quién posee la cualidad segunda y tercera, disipando, de dicho modo, la potencia activa de la diferencia. Porque, siguiendo a Deleuze, el platonismo consiste en la operación continua de expulsar todas las copias que amenazan la integridad y estabilidad de la Idea ${ }^{3}$ :

La finalidad de la división no es, pues en modo alguno, dividir un género en especies, son, más profundamente, seleccionar linajes: distinguir pretendientes, distinguir lo puro y lo impuro, lo auténtico y lo inauténtico [...] El platonismo es la Odisea filosófica; la dialéctica platónica no es una dialéctica de la contradicción ni de la contrariedad, sino una dialéctica de la rivalidad (amphisbetesis), una dialéctica de los rivales o de los pretendientes: la esencia de la división no aparece a lo ancho, en la determinación de las especies de un género, sino en profundidad, en la

\footnotetext{
${ }^{3}$ Respecto a este punto, el estudio de las lógicas aberrantes de David Lapoujade resulta esclarecedor: “Desde el punto de vista que nos ocupa por un instante, la afirmación de la univocidad del ser no consiste solamente en afirmar la diferencia o las multiplicidades como tales; es también una consecuencia necesaria de la crítica al fundamento. En efecto, si el fundamento se derrumba, eso significa que ya no es posible establecer una jerarquía entre pretendiente, distribuidos según series electivas como lo hacía Platón. No hay un sentido eminente del Ser con el cual se relacionaría todos los otros entes en proporción de su conformidad al primer término" (2016 59).
} 
selección del linaje. Seleccionar las pretensiones, distinguir el verdadero pretendiente de los falsos (Id. 1989 256).

Dicho de otra manera, Platón establece el fundamento de una jerarquía de los pretendientes, según la aproximación de cada uno en relación con su representación de la Idea. En ese sentido, Lapoujade sostendrá en torno a la inversión del platonismo deleuziana: “Todas las diferencias entre pretendientes se ve así subordinadas a la semejanza que mantienen entre sí a lo largo de una escala electiva mientras que esa semejanza se vea fundada en la identidad consigo de la Idea [...] Por eso el esfuerzo para remontar más allá del fundamento debe ser llamado inversión del platonismo" (2016 52).

Una clave de lectura similar es la presente en Theatrum Philosophicum de Foucault, en donde la inversión deleuziana se extiende en la elaboración de un movimiento escénico para el pensamiento, la disposición de la filosofía en términos teatrales y, al igual que Zaratustra, en el sincopado de un pensamiento que danza. Dichos gestos, por ambiguos que resuenen en tanto que operación, consisten en una exaltación dispuesta a irrumpir al interior del pensamiento metafísico representacional privilegiando la potencia subversiva del simulacro:

No es un pensamiento por venir, prometido en el más lejano de los recomienzos. Está ahí, en los textos de Deleuze, saltarín, danzante ante nosotros, entre nosotros [...] La filosofía no como pensamiento, sino como teatro: teatro de escenas múltiples, fugitivas e instantáneas donde los gestos, sin verse, se hacen señales (Foucault 1995 47).

A partir de esta delimitación del teatro como problema filosófico es que se inscribe la subversión del esquema de la filosofía representacional y la restitución de la inmanencia para Deleuze. Lo que nos interesa, aquí, por lo tanto, es indagar aquel desbaratamiento de la jerarquía ontológica: “El problema ya no concierne a la distinción Esencia-Apariencia, o Modelo-copia. Esta distinción opera enteramente en el mundo de la representación; se trata de introducir la subversión en este mundo" (1989 263). En ese sentido, bien hace Foucault al enlazar la inversión del platonismo en Deleuze con la aparición de un punto relevante que amenaza con franquear en lo más profundo de la filosofía platónica: la doctrina del juicio de división platónica. Esto lo podemos entender en la supresión de la diferencia platónica, es decir, en pensar la abundancia de lo impalpable y en todo aquello que se resta fuera del modelo: "Invertir, con Deleuze, el platonismo, es desplazarse insidiosamente por él, bajar un peldaño, llegar hasta ese pequeño gesto -discreto, pero moral- que excluye el simulacro" (Foucault 1995 11). En efecto, para Deleuze el problema consiste en pensar las condiciones necesarias para que la expresión filosófica comience: 
Pensar se arrastra lánguidamente como una perversión; pensar se repite con aplicación sobre un teatro; pensar se echa de golpe fuera del cubilete de los dados. Y cuando el azar, el teatro y la perversión entran en resonancia, cuando el azar quiere que entre los tres haya esta resonancia, entonces el pensamiento es un trance; y entonces vale la pena pensar (Id. 41).

Así, bien podemos percatarnos que, al considerar la dimensión teatral en Deleuze, nos remitimos a la búsqueda de una filosofía de la "inmanencia pura" que se sustrae al platonismo:

La simulación es el fantasma mismo, es decir, el efecto de funcionamiento del simulacro en tato que maquinaria, máquina dionisíaca. Se trata de lo falso como potencia, Pseudos, en el sentido en que Nietzsche lo dice: la más alta potencia de lo falso. Subiendo a la superficie, el simulacro hace caer bajo la potencia de lo falso [...] Hace imposible el orden de las participaciones, la fijeza de la distribución y la determinación de la jerarquía. Instaura el mundo de las distribuciones nómadas y de las anarquías coronadas (Deleuze 1989 264).

En efecto, nos comentará posteriormente Deleuze, Nietzsche actúa más bien como un director de escena que un filósofo (cf. 2012 32). Y su pensamiento, en tanto que teatro, se constituye en la potencia del simulacro. No se tratará, por tanto, de un teatro de la representación, sino de introducir la subversión al esquema de la metafísica representacional. En el desbaratamiento de la jerarquía fundacional platónica, la inversión del platonismo en Deleuze consiste en pensar una ontología $-\mathrm{y}$, por ende, una estética- que abandone su matriz representacional y mimética. Precisamente, la filosofía representacional en tanto herencia platónica de la cancelación de la diferencia, nos impide pensar la diferencia en sí misma que contiene el simulacro, su carácter anárquico. Al contrario de cualquier esencialismo que caracterice al simulacro, se tratará de afirmar su carácter inasible. Porque el simulacro excede a la representación, es un espacio siempre abierto a fuerzas puras y trazos dinámicos. La inversión del platonismo será la escena que traza en el pensamiento un teatro que exprese intensidades:

El teatro de la repetición se opone al teatro de la representación, así como el movimiento se opone al concepto y a la representación que lo relaciona con el concepto. En el teatro de la repetición se experimentan fuerzas puras, trazos dinámicos [...] un lenguaje que habla antes de las palabras, gestos que se elaboran antes que los cuerpos organizados, máscaras previas a los cuerpos, espectros y fantasmas anteriores a los personajes- todo el aparato de la repetición como "potencia terrible" (Id. 34).

A modo de resumen, lo que hay tras la radicalidad del gesto deleuziano consiste en subvertir la metafísica occidental desde el teatro, incorporar elementos teatrales y volver a aquella potencia subversiva que el platonismo, insistentemente, procuró 
manejar. Foucault en El filósofo enmascarado nos describe aquella redefinición de la filosofía y sus formas de expresión buscada por Deleuze:

La filosofía es el movimiento por el que, no sin esfuerzos y tanteos y sueños e ilusiones, nos desprendemos de lo que está adoptado como verdadero y buscamos otras reglas de juego. La filosofía no es sino el desplazamiento y la transformación de los marcos de pensamiento; la modificación de los valores recibidos y todo el trabajo que se hace para pensar de otra manera, para hacer algo otro (1999 223)

\section{Diferencia y repetición: un tratado metafísico de orden teatral}

Tal como se mencionó anteriormente, el proyecto de la ontología deleuziana en Diferencia y repetición comprenderá el vitalismo nietzschenano desde una óptica teatral. Particularmente, en el procedimiento de un movimiento escénico que interviene en la filosofía desatando una teatralidad que le es propia:

El nacimiento de la tragedia no es una reflexión sobre el teatro antiguo, sino la fundamentación práctica de un teatro del porvenir [...] Zaratustra está concebido por entero en la filosofía, pero también, por entero, para el escenario. Todo está en él sonorizado, visualizado y puesto en movimiento, en marcha y en danza [...] Aquí también se trata, para Nietzsche, de colmar el vacío interior de la máscara en un espacio escénico, multiplicando las máscaras superpuestas, inscribiendo en esa superposición la omnipresencia de Dionisos, colocando en ella tanto lo infinito del movimiento real como la diferencia absoluta en la repetición del eterno retorno (Deleuze 2012 33).

Lo cierto es que inquirir un estado de teatralidad en la filosofía, en estricto rigor, tiende a resultar problemático, pues, en Nietzsche -a diferencia de Sartre, Camus, Guattari o Badiou- no existe realización alguna respecto al teatro. Según Pavis la teatralidad vendría a designar una cierta especifidad del hecho teatral, al igual, que la literaridad determina a la literatura ( $c f .1989$ 470). Por lo demás, resulta evidente que aquel goce de autonomía vino a disolver las retóricas que subyugaban el teatro a la dramaturgia, como un género particular. Sin embargo, ¿es la especificidad de la teatralidad un fenómeno privativo del hecho teatral? Innegablemente, el calificativo de teatral traspasa diversas esferas no exclusivas al medio escénico, de tal grado, que la mayor parte de nuestro desenvolver cotidiano se conforma teatralmente. Cada situación posee su escenario, un determinado ordenamiento de los cuerpos, un juego de personajes, vestuarios, máscaras y roles. Una ceremonia, ir al médico, asistir a clases, comprar en una tienda, nos traslada a pensar que, en efecto, la sociedad misma exhibe en distintos niveles de teatralidad que determinan la pertinencia de respectivas situaciones teatrales. Desde la disciplina de la misa dominical hasta la insubordinación de los cuerpos en una marcha autorizada, todo acontece como un plano escénico con relación a un reglaje. Aquel 
reglaje de los cuerpos y afectos, nos comentará Lyotard, desenvuelve nuestro imaginario espacio-temporal contemporáneo mediante sucesivos planos escénicos. En suma, la capacidad de escenificación no corresponde a una actividad exclusivamente artística:

Si la escenificación es una ordenación de movimientos, ello no se debe a que sea propaganda (en beneficio de la burguesía, dirán unos; de la burocracia, añadirán otros), sino porque es propagación. Igual que la libido debe renunciar a esos desbordamientos perversos para propagar la especie en la genitalidad normal, y deja constituirse el "cuerpo sexuado" con esa única finalidad, de la misma manera la película que produce el artista en la industria capitalista (y toda la industria conocida en la actualidad lo es) y que resulta, como se ha dicho, de la eliminación de los movimientos aberrantes, de los gestos inútiles, de las diferencias de pura consunción, está compuesta como un cuerpo unificado y propagador, un conjunto reunido y fecundo, que va a transmitir lo que vehicula en lugar de perderlo. La diégesis encierra la síntesis de los movimientos en el orden de los tiempos, la representación perspectivista en el orden de los espacios (1981 55)

Conjeturaremos, entonces, que aquel es el problema que le interesa a Deleuze: la dramatización de los espacios y las ideas, que circunscriben relaciones de diferencias y singularidades dispuestas en el bosquejo de una teatralidad:

El mundo es un huevo, pero el huevo es él mismo un teatro: teatro de puesta en escena donde los papeles tienen más importancia que los actores, los espacios que los papeles, las Ideas que los espacios. Aún más, en virtud de la complejidad de una Idea y de sus relaciones con otras Ideas, la dramatización espacial se juega en varios niveles [...] Hay, por doquier, una puesta en escena en varios niveles (Deleuze, 2012 326).

A partir de aquello, Deleuze determina que la teatralización de la investigación filosófica parece ser la vía más prometedora para hacer efectivo el ejercicio de pensar. Considerando que la filosofía, en tanto que imagen dogmática del pensamiento, es aquello que impide hacer su ejercicio efectivo. La imagen del pensamiento (moral, representacional, de la estructura del reconocimiento), dominio en que habita la filosofía representacional, se conforma inauguralmente con la pretensión de la eliminación de todos los presupuestos. A modo de ejemplo, siguiendo a Deleuze, el cogito cartesiano emerge con la intención de eliminar los presupuestos de animal y racional, sin embargo, en dicha operación se infiltran una serie de presupuestos "subjetivos" e implícitos, propios de la filosofía del sujeto. Desde aquí Deleuze esbozará un problema que entrecruza todo el dominio de la filosofía, dicho de otro modo, su imposibilidad de comenzar verdaderamente sin presupuestos 4 :

${ }^{4}$ Los presupuestos de la filosofía serán para Deleuze aquellas filtraciones del pensamiento que determinan profundamente nuestra concepción del significado del pensar, piezas inamovibles que aún no se han cuestionado pues se inquiere que ellos representen la forma natural del pensar. Estos 
Los postulados no necesitan ser dichos: actúan mucho mejor en silencio; en ese presupuesto de la esencia como en la elección de los ejemplos; ellos forman parte de la imagen dogmática del pensamiento. Aplastan el pensamiento bajo de una imagen que es la de lo Mismo y lo Semejante en la representación, pero que traiciona en lo más profundo lo que significa pensar, enajenando las potencias, de la diferencia y la repetición, del comienzo y el recomienzo filosófico (2012 255).

Esta definición del pensamiento filosófico, tan sencilla como problemática, refiere a la naturaleza del pensamiento se presupone constantemente: "Las condiciones de una verdadera crítica de una verdadera creación son las mismas: destrucción de la imagen del pensamiento que se presupone a sí mismo, génesis del acto de pensar en el pensamiento mismo" (2012 215). Por lo que sólo aquel que desborda la forma de la representación y del reconocimiento general en el pensamiento, se encuentra en un sentido extramoral:

Lo primero en el pensamiento es la fractura, la violencia, el enemigo; y nada supone la filosofía, todo parte de una misosofía. No se debe contar con el pensamiento para sentar la necesidad relativa de lo que se piensa, sino por el contrario con la contingencia de un encuentro con lo que fuerza a pensar, para levantar y erigir la necesidad absoluta de un acto de pensar, de una pasión de pensar (Ibíd.)

En este marco, Nietzsche y Kierkegaard, según Deleuze, poseen una fuerza común que les permitió hacer de la filosofía algo nuevo y con ello un equivalente al teatro; concebir la filosofía sin presupuestos con aquella fuerza intempestiva del pensar. Al igual que con la distinción platónica entre el simulacro y las copias, el pensamiento representacional obedece -como señala reiteradas veces Nietzsche- a causas morales:

Cada uno de ellos, a su manera, hizo de la repetición no sólo una potencia propia del lenguaje y del pensamiento, un pathos y una patología superior, sino también la categoría fundamental de la

presupuestos entrecruzan la historia de la filosofía y son los siguientes: 1) postulado del principio o de la cogitatio natura universalis (buena voluntad del pensador y buena naturaleza del pensamiento); 2) postulado del ideal o del sentido común (el sentido común como concordia facultatum, y el buen sentido como distribución que garantiza esa concordia); 3) el postulad del modelo o del reconocimiento (el reconocimiento que invita a todas las facultades a aplicarse sobre un objeto que se supone es el mismo, y la posibilidad de error que se desprende de ello en la repartición); 4) postulado de la representación (cuando la diferencia es subordinada a las dimensiones de lo Mismo y lo Semejante); 5) postulado de lo negativo del error (entendiendo el error como la expresión de todo lo malo que puede ocurrir en el pensamiento); 6) postulado de la función lógica (el cual considera a la significación como el lugar de la verdad); 7) postulado de la modalidad o de las soluciones (los problemas se definen por su posibilidad de ser resueltos, es decir, se calcan de sus proposiciones); 8) postulado del saber (la subordinación del aprender al saber y de la cultura al método) 
filosofía del porvenir. A cada uno de ellos corresponde un Testamento y también un Teatro, una concepción del teatro y un personaje eminente dentro de él (Deleuze 2012 27).

La dirección al carácter teatral, entonces, guarda relación con una recuperación de aquella potencia inventiva del pensamiento y con ello la fractura de su imagen dogmática. Nos comentará Deleuze haciendo referencia a Artaud que el impulso del pensar es ante todo fisura, una fractura en aquel sentido sedimentado, nauseabundo y descompuesto:

En todo esto Artaud persigue la terrible revelación de un pensamiento sin imagen y la conquista de un nuevo derecho que no se deja representar. Sabe que la dificultad como tal, y su cortejo de problemas y preguntas, no son un estado de hecho, sino una estructura del derecho del pensamiento. Sabe que hay un acéfalo en el pensamiento, un amnésico en la memoria, un afásico en el lenguaje, un agnóstico en la sensibilidad. Sabe que el pensar no es innato, sino que debe ser engendrado en el pensamiento [...] Pensar es crear, y no hay otra creación sino que crear es, ante todo engendrar "pensamiento" en el pensamiento (2012 227).

A partir de dicho punto la filosofía ya no se articularía en relación con una imagen trascendental, sino en el tejido de fuerzas que componen y hacen factible el acto de pensar:

En ese sentido hay algo completamente nuevo que comienza con Kierkegaard y Nietzsche. Ya no reflexionan sobre el teatro a la manera hegeliana. Tampoco hacen un teatro filosófico. Inventan, en la filosofía, un equivalente increíble del teatro, y con ello, fundan ese teatro del porvenir, al mismo tiempo que una filosofía nueva (Id. 32).

Aquella tradición nietzscheana que reclama la dramatización de ideas en oposición a la representación de conceptos: “El teatro de la repetición se opone al teatro de la representación, así como el movimiento se opone al concepto y a la representación que lo relaciona con el concepto" (2012 34). Considerando aquello, la denominada dramatización de la filosofía es descrita por Deleuze en Nietzsche y la filosofía como un método desplegado en el seno de la forma en que el filósofo se cuestiona y elabora las preguntas; organizado en un desplazamiento de todos aquellos presupuestos morales propios de la imagen dogmática del pensamiento que impiden al pensamiento buscar modelos en aventuras más extrañas o comprometedoras:

El método consiste en esto: relacionar un concepto con la voluntad de poder para hacer de él el síntoma de una voluntad sin la cual no podría ni siquiera ser pensado (ni el sentimiento experimentado, ni la acción llevada a cabo). Semejante método corresponde a la pregunta trágica. Es propiamente el método trágico. $\mathrm{O}$, para ser más precisos, si despojamos a la palabra "drama" de todo el pathos dialéctico y cristiano que compromete su sentido, es el método de dramatización (2016 112). 
Es decir, un pensamiento que se constituye no en una elaboración abstracta de los conceptos, sino en el seno de una sintomatología de un plano de intensidades y fuerzas de una voluntad que quiere algo. Eduardo Pellejero, muy probablemente, uno de los primeros comentaristas de habla castellana dedicado a analizar la cuestión teatral en el pensamiento de Deleuze sobre este cruce entre el pensamiento nietzscheano y el deleuziano nos comenta lo siguiente, ya señalando aquel trabajo de fuerzas desplazado por el orden representacional:

Teatro antiguo, por lo que respecta a la historia del teatro, pero también por lo que respecta a la crítica deleuziana. Un teatro de la representación, al fin y al cabo, en el sentido lato de la palabra, respecto del cual Deleuze ya tomaba sus distancias cuando buscaba determinar el método dramático que caracterizaba sus libros anteriores. Porque la denuncia de los sistemas materiales por detrás de las representaciones instituidas, como vimos, no apelaba ni podía apelar a un teatro de la representación. Al menos en la medida en que Deleuze, como "dramaturgo", se imponía por objeto la destrucción de la identidad de las cosas representadas (valores, conceptos, acontecimientos) y de las figuras por detrás de la identidad de la propia representación (autor, historia, espectador), abriéndolas a las relaciones de fuerzas y los problemas singulares de los cuales dependía su existencia (Pellejero 2005 49).

Es decir, la idea de un teatro que transita por un trabajo de fuerzas y voluntad al interior del pensamiento:

La pregunta “¿Qué es?" resulta abstracta para Deleuze, en la medida que presupone que la esencia tiene la forma de una quiditas estática. La pregunta “¿Quién?", por el contrario, implica un desplazamiento hacia el terreno de la voluntad y de los valores, donde rige una dinámica del ser inmanente, caracterizada por fueras de diferenciación interna y eficiente (2005 27).

\section{Consideraciones finales}

Foucault en Theatrum Philosophicum, inscribe la fase inicial del pensamiento deleuziano en aquella tradición nietzscheana destinada a la inversión del platonismo pero, esta vez, bajo una óptica de lo teatral que esboza una ontología de los cuerpos y las potencias afectivas:

No es un pensamiento por venir, prometido en el más lejano de los recomienzos. Está ahí, en los textos de Deleuze, saltarín, danzante ante nosotros, entre nosotros [...] La filosofía no como pensamiento, sino como teatro: teatro de escenas múltiples, fugitivas e instantáneas donde los gestos, sin verse, se hacen señales (1995 47).

Sostendremos, a modo de conclusión, que este acceso al teatro tendrá como propósito poner en suspensión la imagen representacional del pensamiento: “La equivocación de la filosofía consiste en presuponer en nosotros una buena voluntad del pensar, un deseo, un amor natural de lo verdadero. Por esto la 
filosofía sólo llega a verdades abstractas que no comprometen a nadie y no transforman nada" (1972 25). Traer el teatro a la metafísica consistirá, por lo tanto, en un gesto de rebeldía, aquel enemigo disipador de sentido comprometido con una política del cuerpo y que viene a desconfigurar el sistema de relaciones sensibles. Pues, ya señalado tempranamente el platonismo, se trata de una lógica de simulacro que en su violencia desestabiliza las formas del pensamiento, una sutura de la jerarquía para dar libre paso al juego teatral de las anarquías coronadas:

La simulación es el fantasma mismo, es decir, el efecto de funcionamiento del simulacro en tanto que maquinaria, máquina dionisíaca. Se trata de lo falso como potencia, Pseudos, en el sentido en que Nietzsche lo dice: la más alta potencia de lo falso. Subiendo a la superficie, el simulacro hace caer bajo la potencia de lo falso [...] Hace imposible el orden de las participaciones, la fijeza de la distribución y la determinación de la jerarquía. Instaura el mundo de las distribuciones nómadas y de las anarquías coronadas (Deleuze 1989 264).

En ese sentido, tal como se abordó a lo largo de este recorrido, Deleuze manejará una idea del fenómeno de la teatralidad no restrictiva al teatro como tal. Sostendremos que la inversión deleuziana se extiende en la elaboración de un movimiento escénico para el pensamiento. El ejercicio por lo tanto consistirá pensar en el seno de la univocidad del ser y el sentido una ontología de lo menor, entramada en un distanciamiento de la lógica de la identidad hasta su desvanecimiento completo.

\section{Bibliografía}

Aristóteles. La poética. Madrid: Gredos, 2011.

Artaud, Antonin. El teatro de la crueldad. Buenos Aires: Cuenco de Plata, 2014.

Badiou, Alain. Imágenes y Palabras: escritos sobre cine y teatro. Buenos Aires: Manantial, 2005.

Chevallier, Jean-Frédéric. Deleuze et le thêâtre. Paris: Les solitaires intempestifs, 2015.

Deleuze, Gilles. Proust y los signos. Barcelona: Anagrama, 1972.

Deleuze, Gilles. Lógica del sentido. Barcelona: Paidos, 1989.

Deleuze, Gilles. «L'épuisé» en Quad et autres pièces pour la télévision. Paris: Les Éditions de Minuit, pp. 57-103, 1992.

Deleuze, Gilles. Superposiciones. Córdoba: Ediciones Artes del Sur, 2003. 
Deleuze, Gilles. Diferencia y repetición. Buenos Aires: Amorrortu, 2012.

Deleuze, Gilles. Nietzsche y la filosofía. Barcelona: Anagrama, 2016.

Derrida, Jacques. La escritura y la diferencia. Barcelona: Anthropos, 1989.

Descombes, Vicent. Lo mismo y lo otro. Madrid: Catedra, 1988.

Foucault, Michel. Theatrum Philosophicum. Barcelona: Anagrama, 1995.

Foucault, Michel. Estética, ética y hermenéutica. Barcelona: Paidos, 1999.

Lapoujade, David. Los movimientos aberrantes. Buenos Aires: Cactus, 2016.

Lacoue-Labarthe, Philippe. La imitación de los modernos (tipografías 2). Buenos Aires: La Cebra, 2010.

Lyotard, Jean-François. Los dispositivos pulsionales. Madrid: Fundamentos, 1981.

Nietzsche, Friedrich. El nacimiento de la tragedia. Madrid: Alianza, 2015.

Pavis, Patrice. Diccionario de teatro: dramaturgia, estética y semiología. Paidos, Barcelona, 1989.

Pellejero, Eduardo. “Deleuze y el teatro de la filosofía. Dramatización, minorización y perspectivismo". Devenires VI, 12 (2005): 20-68. 